\title{
Determinants of students' willingness to accept a measles-mumps-rubella booster vaccination during a mumps outbreak: a cross-sectional study
}

\author{
Hanna W. Donkers ${ }^{1,2}$, Jeannine L. A. Hautvast ${ }^{1,3^{*}}$, Reinier P. Akkermans ${ }^{2}$, Corien M. Swaan ${ }^{4}$,
} Wilhelmina L. M. Ruijs ${ }^{1,4}$ and Marlies E. J. L. Hulscher ${ }^{1,2}$

\begin{abstract}
Background: Despite high vaccination coverage, a mumps outbreak that affected mainly vaccinated university students and their contacts took place in the Netherlands in the period 2009-2012. We presented university students with a hypothetical case in which we offered them a measles, mumps, and rubella (MMR) booster vaccination to control the mumps outbreak. The aim of this study was to get insight into the determinants of university students' willingness to accept this vaccination.
\end{abstract}

Methods: A questionnaire containing 38 items was developed for the purpose of assessing students' willingness and the psychosocial and social demographic determinants influencing their willingness to accept an MMR booster vaccination. In addition, we explored how organisational characteristics influenced the willingness to be vaccinated. Data were collected at six Dutch universities; a total of 790 students from various faculties were invited to participate. This was a convenience sampling procedure.

Results: 687 university students participated (response rate $87.0 \%$ ) and $60.4 \%$ of the participants said they would be willing accept the hypothetical MMR booster vaccination. The perceived seriousness of mumps (OR 6.1) was the most important predictor of willingness to accept vaccination. Students who expected the MMR vaccination to be effective and to prevent individual illness and who believed their own vaccination would help stop the epidemic were more likely to be willing than others. The students were more willing to accept vaccination when they perceived that the social norms of significant others and the government favoured vaccination. Organisational characteristics, such as offering vaccination cost free and offering it at the university site, increased students' willingness.

Conclusion: During a mumps outbreak, university students were generally willing to accept a hypothetical MMR booster vaccination. Risk perception, outcome expectations, perceived social norms, and organisational characteristics should be taken into account in the planning of any vaccination campaign for university students during an outbreak of an infectious disease.

Keywords: Mumps outbreak, MMR booster, Vaccination uptake, Willingness to accept vaccination, University students

\footnotetext{
* Correspondence: Jeannine.Hautvast@radboudumc.nl

${ }^{1}$ Radboud Institute for Health Sciences, Department of Primary and

Community Care, Radboud University Medical Centre, P.O. Box 9101, 117, 6500 HB Nijmegen, The Netherlands

${ }^{3}$ Public Health Service of Gelderland-Zuid, Nijmegen, The Netherlands

Full list of author information is available at the end of the article
} 


\section{Background}

The Dutch National Immunisation Programme (NIP) has been offered to prevent infectious diseases via vaccination since 1957 [1]. This programme has successfully decreased the incidence of vaccine-preventable diseases including measles and poliomyelitis. The measles, mumps, and rubella (MMR) vaccine that contains the Jeryl Lynn genotype A mumps virus strain was introduced in 1987 and is administered in a two-dose schedule at the ages of 14 months and 9 years. Vaccination coverage rates in the Netherlands are high. Full MMR vaccination coverage of 10-year-old children was $93.9 \%$ in 2013 [2].

Since the introduction of the MMR vaccine, several mumps outbreaks have occurred in the Netherlands. Mumps broke out among vaccinated college students in 2004 [3] and among children living in a community with low vaccination coverage in the period 2007-2008 [4]. The most recent outbreak affected mainly vaccinated university students and their contacts in the period 2009-2012, and it still affects the general population, although to a lesser extent $[5,6]$. Presumably, many factors facilitated the transmission of mumps from student to student [3, 5-7]. High rates of social interaction and shared accommodation maintained an environment of close contact. There was a mismatch of the circulating virus (genotype $\mathrm{D}$ ) with the vaccine virus, effectiveness of the vaccine is reduced (waning immunity) and less natural mumps circulation due to mass vaccination reduced the immunity of the population. Several other countries reported similar outbreaks among vaccinated college students and adolescents [8-11]. The health authorities maintain regular outbreak control aimed at reducing the impact of the outbreak by offering a dose of the MMR vaccine to each student who is not fully vaccinated (i.e., any student previously received only one MMR dose or none at all) [12-14]. The National Institute for Public Health and the Environment (RIVM) coordinates national outbreak responses in the Netherlands. During the most recent mumps outbreak among university students, the responses included raising awareness of mumps, surveillance, outbreak investigations, and providing catch-up vaccination to unvaccinated or incompletely vaccinated students $[15,16]$.

Since the NIP does not target students [1], knowledge about vaccinating university students as a target population is limited. It is important to get insight into the determinants that influence the students' decisions about whether to accept vaccination, since high vaccination rates are important in controlling outbreaks and students may sometimes be specific target groups. Vaccination campaigns targeting students during outbreaks could benefit from increased understanding why students would be willing to be vaccinated. The aim of the current study was to get insight into students' willingness to accept vaccination during the most recent outbreak. Regardless of their current vaccination status, we presented the university students with a hypothetical case that offered them MMR booster vaccination to control the mumps outbreak. Our research questions were: How many students would be willing to accept the hypothetical MMR booster vaccination? What student characteristics and what social demographic and psychosocial determinants are related to students' willingness to accept vaccination? What organisational characteristics influence their willingness?

\section{Methods \\ Sample and procedure}

This descriptive study has a cross-sectional design. We developed a questionnaire to assess the determinants of students' willingness to accept a hypothetical MMR booster vaccination. The study population consisted of Dutch-speaking university students. We selected 6 of 13 Dutch universities for diversity in the geographic distribution of the reported mumps cases and subsequent Municipal Health Service information campaigns to raise awareness about mumps.

We based the calculation of the sample size on the precision of the estimated proportion of the outcome variable 'willingness to accept MMR vaccination'. Since no estimate of this proportion was available, we used the value $50 \%$ in the calculation. A total of 267 were needed on the basis of a precision of $6 \%$ and a $95 \%$ confidence interval (CI). We multiplied this number with a design effect (variance inflation factor) to account for clustering between universities. On the basis of an intra-cluster correlation coefficient (ICC) of 0.03 , we calculated the total sample size of students to be 600 . We aimed to include at least 100 students per university. Two researchers visited each university for 1 day in April or May 2012 and invited all students located in food courts, recreation areas, and libraries to participate. We selected two locations at each university to reach students from various faculties. All students present were individually asked to participate. Verbal consent was obtained from students who were willing to participate. Printed questionnaires were handed out to consenting students, and they were asked to complete them (this took averagely 10 to $15 \mathrm{~min}$ ). The researchers collected the questionnaires immediately on completion. The students who did not consent were asked for their reasons.

\section{Questionnaire and variables}

The content of the questionnaire was based on the results of our explorative qualitative study [17]. It included organisational characteristics and several concepts derived from the Theory of Planned Behaviour [18] and the Social Cognitive Theory [19]. In this preceding qualitative study, we interviewed 22 unvaccinated students 
who had recently accepted catch-up MMR vaccination $(n=10)$ or had not $(n=12)$. This study provided extensive information about the broad spectrum of determinants that influenced whether the students accepted the vaccination. The questionnaire was pre-tested and revised in two rounds.

\section{Willingness}

The primary outcome measure was students' willingness to accept MMR vaccination. After presenting participants with written information about the mumps outbreak, we described a hypothetical case in which an MMR booster vaccination would be offered to all students in order to stop the outbreak. Willingness ('I would definitely accept this MMR booster vaccination') was measured with one item on a four-point scale: "totally agree", "agree", "disagree", "totally disagree".

\section{Student characteristics}

We assessed gender, year of study, university city, and study programme.

\section{Social demographic determinants}

We assessed several determinants: age, country of birth, living situation, and health status. The participants were asked whether they had participated in the NIP as children ('yes', 'no', 'I do not know' and 'partially'). The students' knowledge of the latest mumps outbreak in the Netherlands ('Do you know there is an ongoing mumps outbreak among students? yes, no') was measured with one item.

\section{Psychosocial determinants}

The participants were asked whether they agreed with 19 items designed to assess psychosocial determinants of their willingness to be vaccinated. All items were measured on a four-point scale: 'totally agree', 'agree,' 'disagree,' 'totally disagree'. Attitude toward vaccination was assessed with three items (e.g., 'I generally do not object to vaccination'). Risk perception was measured with four items about perceived severity and perceived susceptibility (e.g., 'Mumps can have serious consequences for my own health' and 'I think I have a high risk of catching mumps'). Outcome expectations were measured with nine items about perceived benefits and anticipated regret (e.g., 'I think vaccination decreases my chances of getting mumps' and 'If the epidemic turns out not to be severe, I would regret getting vaccinated'). The perceived social norm was measured with three items (e.g., 'I would discuss the advice to get vaccinated with significant others').

\section{Organisational characteristics}

The questionnaire contained eight questions about organisational characteristics to find out which ones influenced willingness to accept the hypothetical MMR booster.
Questions about organisational characteristics that might influence the accessibility of getting vaccination included the vaccination venue (e.g., a university site or a location of the Municipal Health Service), price (e.g., cost free or 20 euros), invitation type (e.g., personal or via a newspaper), time constraints (a busy study period), and a financial incentive (a small reward after vaccination). Responses to these items were recorded on a four-point scale: 'yes, certainly', 'yes, probably', 'no, probably not', 'no, certainly not'.

\section{Data analyses}

We used SPSS for Windows Release 19 for the descriptive statistics to describe the participants' social demographic variables. The scores for the psychosocial determinants and the item measuring willingness (the primary dependent variable) were converted to dichotomous scores (agree - disagree). Spearman correlation coefficients were computed since our data were not normally distributed. Only the determinants that showed statistically significant associations with willingness to be vaccinated $(p<0.05)$ and with correlation $r \geq 0.25$ were entered in a multilevel logistic regression analysis $[20,21]$. Because of the hierarchical structure of our study (students nested within universities), we based these analyses on the logistic mixed effect model (PROC GLIMMIX in SAS V9.2). Both fixed and random effects can be analysed in this model. We used a model with a random intercept; all other variables were fixed. We considered $p<0.05$ statistically significant. We performed descriptive statistics for the eight organisational characteristics.

\section{Results}

\section{Characteristics of the respondents}

A total of 687 Dutch university students completed the questionnaire. The number of questionnaires returned from the universities ranged from 102 to 121 . The total response rate was $87.0 \%$, ranging from $80.8 \%$ to $95.2 \%$ per university. The 103 non-consenting students all reported refusing to participate due to self-reported time constraints. None of the students who refused to participate mentioned religious or philosophical objections to vaccination.

Of all the participants, $50.2 \%$ were male. Students from all study programmes and years participated. The mean age of the participants was 21.3 years (SD 2.7 years). Most of the respondents, $87.3 \%$, had Dutch citizenship, and $72.7 \%$ of them lived away from home. Most students reported good health: $96.8 \%$ assessed their health as excellent, very good, or good. Most of the participants, $90.5 \%$, had received all National Immunisation Programme (NIP) vaccinations during childhood; $2.2 \%$ did not participate; $1.8 \%$ had received at least one vaccination; and $5.5 \%$ had no knowledge of their 
vaccination status. Of all participants, $38.7 \%$ knew there was an ongoing mumps outbreak among university students in the Netherlands, with a city range from $18.5 \%$ (Eindhoven) to $61.3 \%$ (Nijmegen).

\section{Vaccination willingness}

A total of 408 participants $(60.4 \%)$ were willing to accept the hypothetical MMR booster vaccination.

\section{Social demographic determinants}

Of the 408 students who were willing to accept the MMR vaccine, $48.8 \%$ were male and $51.2 \%$ were female (Table 1). The willingness of the students from different years of study ranged from $50.4 \%$ (third-year students) to $65.5 \%$ (first-year students). A greater proportion of students studying in Delft were willing to accept vaccination $(75.2 \%)$ than in other cities. Willingness varied among the study programmes as well; the people who studied linguistics, history, or arts were least inclined to accept vaccination (37.8\%).

Table 1 Willingness and student characteristics of a sample of Dutch university students

\begin{tabular}{|c|c|c|c|}
\hline Item & Characteristic & $\begin{array}{l}\text { Study } \\
\text { subjects (\%) }\end{array}$ & $\begin{array}{l}\text { Willing to be } \\
\text { vaccinated (\%) }\end{array}$ \\
\hline & & $n=687$ & $n=408 / 676$ \\
\hline \multirow[t]{3}{*}{ Gender } & Male & $345(50.2)$ & $199(48.8)$ \\
\hline & Female & $342(49.8)$ & $209(51.2)$ \\
\hline & & $n=683$ & $n=404 / 672$ \\
\hline \multirow[t]{5}{*}{ Year of study } & 1 & $260(38.1)$ & $167(65.5)$ \\
\hline & 2 & $147(21.5)$ & $92(63.4)$ \\
\hline & 3 & $134(19.6)$ & $66(50.4)$ \\
\hline & $\geq 4$ & $142(20.8)$ & $79(56.0)$ \\
\hline & & $n=687$ & $n=408 / 676$ \\
\hline \multirow[t]{7}{*}{ University city } & Nijmegen & $119(17.3)$ & $69(58.0)$ \\
\hline & Eindhoven & 119 (17.3) & $67(56.3)$ \\
\hline & Utrecht & $122(17.8)$ & $68(58.1)$ \\
\hline & Delft & $102(14.8)$ & $76(75.2)$ \\
\hline & Amsterdam & $121(17.6)$ & $61(51.7)$ \\
\hline & Maastricht & $104(15.1)$ & $67(65.7)$ \\
\hline & & $n=682$ & $n=406 / 671$ \\
\hline \multirow[t]{6}{*}{ Study programme ${ }^{a}$} & $\begin{array}{l}\text { Social sciences, Business, } \\
\text { Law }\end{array}$ & $226(33.1)$ & $129(58.1)$ \\
\hline & $\begin{array}{l}\text { Technique, Industry, } \\
\text { Engineering }\end{array}$ & $179(26.2)$ & $113(63.5)$ \\
\hline & Healthcare, and Welfare & $141(20.7)$ & $82(59.0)$ \\
\hline & Physics Mathematics, IT & $55(8.1)$ & $42(76.4)$ \\
\hline & Linguistics, History, Arts & $39(5.7)$ & $14(37.8)$ \\
\hline & Other & $42(6.2)$ & $26(65.0)$ \\
\hline
\end{tabular}

abased on the International Standard Classification of Education (ISCED) division [35]
Spearman correlations with vaccination willingness were calculated for student characteristics and social demographic variables including gender, year of study, university city, study programme, living situation, health status, NIP participation, and knowledge of the epidemic. Only the year of study correlated statistically significantly with willingness $(r<0.25)$. These variables were not included in further analyses because of the weak correlation.

\section{Psychosocial determinants}

Table 2 presents the results from the descriptive statistics of the dichotomous psychosocial determinants and the Spearman correlations of their relation with the willingness to be vaccinated. All items were associated with willingness $(p \leq 0.05)$. Correlations with willingness $(r \geq$ 0.25 ) were found for nine psychosocial variables related to attitude, risk perception, outcome expectations, and perceived social norms.

These nine determinants were analysed in a multilevel logistic regression model. Table 3 presents the psychosocial determinants showing a statistically significant $(p<$ $0.05)$ relation to students' willingness to accept MMR booster vaccination in the multilevel analysis. These seven variables explained $58 \%$ of the variance in willingness $\left(\mathrm{R}^{2}\right)$. One item relating to the perceived seriousness of mumps (risk perception 1) showed the most powerful influence on willingness to be vaccinated (OR 6.1; CI $95 \%$ 3.54-10.35) with a higher risk perception that resulted in greater willingness. Students who believed mumps was not serious for them were less likely to accept vaccination (OR 0.25; CI 95 \% 0.14-0.43). Students who expected vaccination to prevent their own illness (outcome expectation 4; OR 2.8, CI $95 \%$ 1.47-5.37) and those who expected that individual vaccination would help stop the epidemic (outcome expectation 7; OR 2.5, CI $95 \%$ 1.32-4.67) were more likely to be willing. Expecting to regret vaccination if the epidemic turned out not to be severe (outcome expectation 9; OR 0.5, $95 \%$ CI 0.33-0.90) resulted in less willingness. Perception of the social norm influenced willingness as well. If significant others thought vaccination was important (social norm 2; OR 1.7, 95 \% CI 1.01-2.73) or if the government advised vaccination (social norm 3; OR 2.2, $95 \%$ CI 1.40-3.60), students were more likely to accept vaccination.

\section{Organisational characteristics}

To determine which organisational characteristics influence their willingness, we presented all 408 students who were initially willing to accept the MMR vaccine with statements about accepting vaccination in various situations (Table 4). Almost all of the students who were initially willing $(97.8 \%)$ were willing to accept the vaccination if it was offered cost free. If the students had to pay for vaccination, $58.4 \%$ of all students who were 
Table 2 Descriptive statistics and Spearman correlation of psychosocial determinants and willingness to be vaccinated

\begin{tabular}{|c|c|c|c|c|}
\hline Questionnaire statement & Concept & Agreement $n(\%)$ & Spearman's rho & Significance \\
\hline I have no objections to vaccination in general & Attitude 1 & $646(94.6)$ & 0.209 & $<0.0001$ \\
\hline I sometimes doubt the safety of vaccinations & Attitude 2 & $229(33.4)$ & -0.156 & $<0.0001$ \\
\hline Vaccinating all students is costly and therefore not desirable & Attitude 3 & $171(25.1)$ & -0.267 & $<0.0001$ \\
\hline I think mumps can have serious consequences for my own health & Risk perception 1 & $483(70.8)$ & 0.548 & $<0.0001$ \\
\hline I think I have a high risk of catching mumps & Risk perception 2 & $108(15.9)$ & 0.208 & $<0.0001$ \\
\hline It is better to live through mumps, so I would not get vaccinated & Risk perception 3 & $52(7.7)$ & -0.158 & $<0.0001$ \\
\hline I do not think mumps is serious for me, so I would not get vaccinated & Risk perception 4 & $180(26.6)$ & -0.531 & $<0.0001$ \\
\hline Possible side effects of vaccination stop me from getting vaccinated & Outcome expectations 1 & $281(41.6)$ & -0.185 & $<0.0001$ \\
\hline I doubt the safety of the MMR vaccine & Outcome expectations 2 & $91(13.5)$ & -0.134 & 0.010 \\
\hline $\begin{array}{l}\text { The MMR vaccination does not work well, so I would not get } \\
\text { vaccinated }\end{array}$ & Outcome expectations 3 & $95(14.4)$ & -0.101 & 0.010 \\
\hline I would accept vaccination to prevent myself from becoming ill & Outcome expectations 4 & $530(77.9)$ & 0.515 & $<0.0001$ \\
\hline As a result of intensive student contacts, mumps cannot be stopped & Outcome expectations 5 & $210(31.0)$ & -0.150 & $<0.0001$ \\
\hline I think vaccination decreases my chances of getting mumps & Outcome expectations 6 & $624(91.4)$ & 0.275 & $<0.0001$ \\
\hline $\begin{array}{l}\text { I would accept vaccination if it were offered as a means of stopping } \\
\text { the epidemic }\end{array}$ & Outcome expectations 7 & $546(79.8)$ & 0.412 & $<0.0001$ \\
\hline $\begin{array}{l}\text { If I decide not to get vaccinated and I catch the mumps, I would } \\
\text { regret my decision }\end{array}$ & Outcome expectations 8 & $453(66.9)$ & 0.193 & $<0.0001$ \\
\hline $\begin{array}{l}\text { If the epidemic turned out not to be severe, I would regret getting } \\
\text { vaccinated }\end{array}$ & Outcome expectations 9 & $176(26.0)$ & -0.272 & $<0.0001$ \\
\hline I would discuss the advice to get vaccinated with significant others & Social norm 1 & $556(81.8)$ & -0.100 & 0.009 \\
\hline Significant others think it is important for me to get vaccinated & Social norm 2 & $453(67.8)$ & 0.339 & $<0.0001$ \\
\hline The government advises vaccination, so I would accept it & Social norm 3 & $341(50.4)$ & 0.385 & $<0.0001$ \\
\hline
\end{tabular}

initially willing would still accept it. The vaccination venue also influenced the students' willingness. If the venue was the university site, $94.3 \%$ of the students with initial willingness would still accept vaccination compared to $82.6 \%$ when the venue was at a local Municipal Health Service. The number of students willing to accept vaccination decreased if they had time constraints such as a busy study period (68.9\%). Further, $91.8 \%$ of the students who were initially willing would accept vaccination if they received a small reward afterwards. Willingness was influenced by the type of invitation: $94.0 \%$ of the students invited in person would get vaccinated, whereas only $60.6 \%$ would get vaccinated if they were invited by a general call in a newspaper or on the internet.

\section{Discussion}

Our study shows that $60.4 \%$ of Dutch university students were willing to be vaccinated in the hypothetical case of an offer of an MMR booster vaccination to control a mumps outbreak. A greater proportion of respondents based in Delft were willing to accept vaccination (75.2\%) than in the other cities. This was probably due

Table 3 Multilevel multivariate logistic regression analysis of significant determinants willingness to be vaccinated

\begin{tabular}{|c|c|c|c|c|c|c|}
\hline \multirow{2}{*}{$\begin{array}{l}\text { Questionnaire item } \\
\text { think mumps can have serious consequences for my health }\end{array}$} & \multirow{2}{*}{$\begin{array}{l}\text { Concept } \\
\text { Risk perception } 1\end{array}$} & \multirow{2}{*}{$\begin{array}{l}\text { Odds ratio } \\
6.06\end{array}$} & \multicolumn{2}{|c|}{$\begin{array}{l}95 \% \text { Cl for OR } \\
\text { Lower upper }\end{array}$} & \multirow{2}{*}{$\begin{array}{l}t \text { Value } \\
6.59\end{array}$} & \multirow{2}{*}{$\begin{array}{l}\text { Significance } \\
<0.0001\end{array}$} \\
\hline & & & 3.54 & 10.35 & & \\
\hline I do not think mumps is serious for me, so I would not get vaccinated & Risk perception 4 & .25 & .14 & .43 & -4.93 & $<0.0001$ \\
\hline I would accept vaccination to prevent myself from becoming ill & Outcome expectation 4 & 2.80 & 1.47 & 5.37 & 3.12 & 0.0019 \\
\hline $\begin{array}{l}\text { I would accept vaccination if it were offered as a means of stopping } \\
\text { the epidemic }\end{array}$ & Outcome expectation 7 & 2.48 & 1.32 & 4.67 & 2.83 & 0.0049 \\
\hline $\begin{array}{l}\text { If the epidemic turned out not to be severe, I would regret getting } \\
\text { vaccinated }\end{array}$ & Outcome expectation 9 & .54 & .33 & .90 & -2.35 & 0.0189 \\
\hline Significant others think it is important for me to get vaccinated & Social norm 2 & 1.66 & 1.01 & 2.73 & 2.00 & 0.0454 \\
\hline The government advises vaccination, so I would accept it & Social norm 3 & 2.24 & 1.40 & 3.60 & 3.35 & 0.0009 \\
\hline
\end{tabular}


Table 4 Descriptive statistics of organisational characteristics and willingness to be vaccinated among students who were initially willing ${ }^{\text {a }}$

\begin{tabular}{ll}
\hline Questionnaire item & $\begin{array}{l}\text { Agreement } \\
n(\%)\end{array}$ \\
\hline $\begin{array}{l}\text { I would accept vaccination even if I had to pay for it myself } \\
\text { ( } \pm \text { 20 euros) }\end{array}$ & $237(58.4)$ \\
I would accept vaccination if it were offered free of charge & $397(97.8)$ \\
I would accept vaccination if it were offered at a university site & $383(94.3)$ \\
I would accept vaccination if it were offered at the local & $336(82.6)$ \\
Municipal Health Service & \\
I would accept vaccination even if I were very busy studying & $279(68.9)$ \\
I would accept vaccination if I received a small reward for it & $371(91.8)$ \\
I would accept vaccination if I received a personal invitation & $378(94.0)$ \\
I would accept vaccination if students were invited in & $246(60.6)$ \\
newspaper ads or on the internet &
\end{tabular}

The total number of students who were initially willing was 408

to the large clusters of mumps cases reported from Delft in 2010 [6, 7]. The overall proportion of students who were willing in our study is consistent with the findings of a similar study among university students in the UK [22].

Risk perception was the most important factor associated with willingness to be vaccinated. Over $70 \%$ of the students believed that mumps could have serious consequences for their own health, and students who considered mumps to be serious were more likely to accept MMR vaccination. This finding is consistent with psychosocial theories about preventive behaviours [23, 24] that indicate that perceived seriousness of a health threat induces increased willingness to accept preventive behavioural measures. According to these theories, knowledge of the existence of a health risk, such as a mumps outbreak, is not enough to elicit preventive behaviours such as obtaining vaccination. This is in line with our results, since knowledge did not correlate significantly with willingness. Moreover, to become motivated to protect themselves and accept vaccination, students would have to realize that they are personally at risk. However, in our study, only $16 \%$ of the respondents believed that they had a high risk of catching mumps. This perceived susceptibility was not strongly correlated with vaccination willingness. Similarly, a study [25] of college students' willingness to accept the novel H1N1 vaccine did not show perceived susceptibility to be a statistically significant predictor. Thus, the perceived seriousness of the disease seems to be a more important determinant of getting vaccination than perceived susceptibility.

The perceived benefits of the vaccination (outcome expectation) had a powerful influence on willingness: students were more likely to accept vaccination if they believed that vaccination would reduce their risks of catching mumps and if they believed that accepting vaccination would help end the epidemic. Similar, a study in
England that involved university students and staff during a mumps outbreak and a consecutive immunisation programme [26] also shows that perceived individual benefit is an important factor in the individual's decision to accept vaccination. This can be taken into account in the messages that are part of an information campaign targeting students during an outbreak.

Perceived social norm, or significant others' approval of behaviour, had a substantial influence on willingness to be vaccinated in our study. If significant others thought vaccination is important or if the government advised vaccination, then the students were more likely to accept vaccination. Other studies show that social norms are important factors in decisions about vaccination as well. Hamilton-West [26] reports that actual peer decision to be the most important predictor of vaccination acceptance; American students' willingness to be vaccinated during the H1N1 pandemic was statistically significantly associated with the attitudes of people in their social networks [27]. Therefore, vaccination campaigns targeting students during outbreaks might benefit from using fellow students as role models to promote vaccination.

This study shows that organisational characteristics can negatively influence students' willingness and thus become barriers to their vaccination. Accessibility factors such as the price students have to pay for vaccination, the location where vaccination is offered, and the manner of inviting students resulted in variation of the proportions of students who were willing. Similarly to our findings, Canadian research about hepatitis B immunisation of healthcare students [28] and research into factors affecting the immunisation status of American students [29] shows the need for a low-cost vaccine, since payment can be a barrier to students being vaccinated. Another method to increase vaccination to consider is offering a reward; however, this might lead to ethical issues and therefore requires thorough deliberation before implementation in practice.

Social demographic determinants such as gender, study programme, study year, living situation, health status, knowledge of the latest mumps outbreak, and acceptance of NIP vaccinations in childhood were not directly related to willingness to be vaccinated. These findings are in accordance with earlier research into determinants of Dutch parents' intentions to vaccinate their children [30].

A strength of this study is the large sample of respondents who participated because of our personally visiting universities and asking students to participate. However, this procedure for convenience sampling may limit the generalisation of the results. Only students present in public areas of the selected universities were approached, which might have introduced a selection bias. Nevertheless, the social demographics of the students in this sample did not differ from those of average Dutch students 
[31]. Our qualitative study among incompletely vaccinated students that we conducted during the mumps outbreak in the Netherlands has revealed critical vaccination attitudes concerning side effects and vaccine effectiveness [17]. Although 103 students refused to participate due to self-reported time constraints, there is no reason to believe that this attrition is selective with regard to students with critical vaccination attitudes. In general, the students were not aware of the study subject before they refused to participate and none of them said that they declined to participate because of religious or philosophical objections to vaccination.

Even though our study shows that students were generally willing to accept the MMR booster vaccination during an outbreak, there is no conclusive evidence that routine administration of a third dose of MMR vaccine is an effective means of outbreak control [32-34]. Our study included students regardless of their vaccination status. This limits generalisation to the student population targeted recently during the mumps outbreak, since only incompletely vaccinated students were actually offered vaccination. Future research aimed at identifying determinants that influence the behaviours of incompletely vaccinated students who did not respond to the vaccination offer could therefore be valuable.

\section{Conclusions}

This study provided valuable insight into students' willingness to be vaccinated and into related determinants when presented a hypothetical scenario in which an MMR booster vaccination was offered as a means of controlling an MMR outbreak. Risk perception, outcome expectations, perceived social norms, and organisational characteristics should be taken into account in the planning of an actual vaccination campaign for students during an infectious disease outbreak.

\section{Ethical considerations}

The research ethics committee of Radboud University Medical Centre of Nijmegen approved this study: CMO number 2011/411. Participation in this study was voluntary, and the respondents could withdraw from participation at any time. We obtained the respondents' implicit informed consent by providing them with oral and written explanations of the nature of the study before they answered the questionnaire.

\section{Competing interests}

All authors declare that they have no competing interests.

The Netherlands Organisation for Health Research and Development supported this work [grant number 125050004]. This study is a part of the outbreak study Mumps virus transmission in vaccinated populations. The funders had no role in study design, data collection and analysis, decision to publish, or preparation of the manuscript.

\section{Authors' contributions}

$H D, J H, R A, W R, C S$, and MH designed the study; HD was instrumental in the data collection; and $H D$ and RA performed the analyses. $H D, J H, W R$, and $M H$ compiled the draft manuscript; and CS and RA commented. All authors read and approved the final manuscript.

\section{Acknowledgements}

We thank the participating students and universities for their cooperation. For their advice in the study design, we are grateful to the staff of the Municipal Health Services (A. Rietveld, C. Wijkmans, C. Hoebe, B. Wolters, K. Hulshof, and E. Fanoy) and M. van der Sande of The National Institute for Public Health and the Environment (RIVM). We also thank the following interns from Academic Collaborative Centre for Public Health (AMPHI) for their help in collecting the data: L. Kamp, E. Verkerk, D. Brandwagt, H. van Tiel and M. Hoeijmakers. We thank A. Lanen and S. van Roosmalen for their help with English editing.

\section{Author details}

${ }^{1}$ Radboud Institute for Health Sciences, Department of Primary and Community Care, Radboud University Medical Centre, P.O. Box 9101, 117, 6500 HB Nijmegen, The Netherlands. ${ }^{2}$ Radboud Institute for Health Sciences, Scientific Institute for Quality of Healthcare (IQ healthcare), Radboud University Medical Centre, Nijmegen, The Netherlands. ${ }^{3}$ Public Health Service of Gelderland-Zuid, Nijmegen, The Netherlands. ${ }^{4}$ Preparedness and Response Unit, Centre for Infectious Disease Control, National Institute for Public Health and the Environment (RIVM), Bilthoven, The Netherlands.

Received: 21 December 2014 Accepted: 2 June 2015

Published online: 20 June 2015

\section{References}

1. Vaccination schedule for the Netherlands [http//vaccine-schedule.ecdc.europa.eu/ Pages/Scheduler.aspx]

2. Van Lier EA OP, Mulder M, Conyn-van Spaendonck MAE, Drijfhout IH, de Hoohgh PAAM, de Melker HE: Vaccinatiegraad Rijksvaccinatieprogramma Nederland [Immunisation coverage National Immunization Programme in the Netherlands]. In. Bilthoven:Rijksinstituut voor Volksgezondheid en Milieu (RIVM), 2013.Report no:150202001/2013.; 2013.

3. Brockhoff HJ, Mollema L, Sonder GJ, Postema CA, van Binnendijk RS, Kohl $\mathrm{RH}$, et al. Mumps outbreak in a highly vaccinated student population, The Netherlands, 2004. Vaccine. 2010;28(17):2932-6.

4. Wielders CC, van Binnendijk RS, Snijders BE, Tipples GA, Cremer J, Fanoy E, Dolman S, Ruijs W, Boot HJ, de Melker HE, Hahne SJ: Mumps epidemic in orthodox religious low-vaccination communities in the Netherlands and Canada, 2007 to 2009. Euro surveillance: bulletin Europeen sur les maladies transmissibles = European communicable disease bulletin 2011, 16(41).

5. Whelan J, van Binnendijk R, Greenland K, Fanoy E, Khargi M, Yap K, Boot H, Veltman N, Swaan C, van der Bij A, de Melker H, Hahne S: Ongoing mumps outbreak in a student population with high vaccination coverage, Netherlands, 2010. Euro surveillance: bulletin Europeen sur les maladies transmissibles = European communicable disease bulletin 2010, 15(17).

6. Greenland K, Whelan J, Fanoy E, Borgert M, Hulshof K, Yap KB, et al. Mumps outbreak among vaccinated university students associated with a large party, the Netherlands, 2010. Vaccine. 2012;30(31):4676-80.

7. Sane J, Gouma S, Koopmans M, de Melker H, Swaan C, van Binnendijk R, et al. Epidemic of mumps among vaccinated persons, the netherlands, 2009-2012. Emerg Infect Dis. 2014;20(4):643-8.

8. Dayan GH, Quinlisk MP, Parker AA, Barskey AE, Harris ML, Schwartz JMH, et al. Recent resurgence of mumps in the United States. New Engl J Med. 2008;358(15):1580-9.

9. Kay D, Roche M, Atkinson J, Lamden K, Vivancos R. Mumps outbreaks in four universities in the North West of England: Prevention, detection and response. Vaccine. 2011;29(22):3883-7.

10. Stein-Zamir C, Shoob H, Abramson N, Tallen-Gozani E, Sokolov I, Zentner G. Mumps outbreak in jerusalem affecting mainly male adolescents. Eurosurveillance. 2009:14(50):12-4.

11. Mossong J, Bonert C, Weicherding P, Opp M, Reichert P, Even J, et al. Mumps outbreak among the military in luxembourg in 2008: epidemiology and evaluation of control measures. Eurosurveillance. 2009;14(7):7-9.

12. McLean HQ, Fiebelkorn AP, Temte JL, Wallace GS. Prevention of measles, rubella, congenital rubella syndrome, and mumps, 2013 summary 
recommendations of the advisory committee on immunization practices (ACIP). Mmwr Recomm Rep. 2013;62(4):1-34.

13. England PH: Mumps: the green book, chapter 23. Mumps immunisation information for public health professionals. In: Immunisation against infectious disease Mumps: guidance, data and analysis 2013.

14. Steenbergen JE van TA, Beaujean DJMA (ed.): LCl Parotitis epidemica. Netherlands; 2011.

15. Opstelten W, Hahne SJ, van Roijen JH, van Paridon L, Wolters B, Swaan CM Mumps makes a comeback. Ned Tijdschr Geneeskd. 2012;156(43):A5187.

16. Swaan CM WB: Low mumps vaccine uptake among non or incomplete vaccinated students during an outbreak in the Netherlands. In.: National Institute for Public Health and the Environment; 2011.

17. Donkers HWRW, Hautvast JLA, Hulscher MEJL. Final report Workpackage 3 Determinants of vaccine uptake among students offered catch-up vaccination. In. Nijmegen: Radboud university medical centre; 2013.

18. Ajzen I. The theory of planned behavior. Organ Behav Hum Dec. 1991;50(2):179-211.

19. Bandura A. Social foundations of thought and action: a social cognitive theory. Englewood Cliffs. London: Prentice-Hall; 1986

20. Cohen J: Statistical power analysis for the behavioral sciences, 2nd ed. edn. Hillsdale, N.J.: L. Erlbaum Associates; 1988.

21. Cohen J. A power primer. Psychol Bull. 1992;112(1):155-9.

22. Bolton-Maggs D, Conrad D, Keenan A, Lamden K, Ghebrehewet S, Vivancos R. Perceptions of mumps and MMR vaccination among university students in England: An online survey. Vaccine. 2012;30(34):5081-5.

23. Friedman HS. The Oxford handbook of health psychology. New York. Oxford: Oxford University Press; 2011.

24. Suls JM, Wallston KA. Social psychological foundations of health and illness. Malden, Mass. Oxford: Blackwell; 2003.

25. Coe ABGS, Moczygemba LR, Goode JV, Beckner JO. The use of the health belief model to assess predictors of intent to receive the novel (2009) H1N1 influenza vaccine. Inov Pharm. 2012;3(2):1-11.

26. Hamilton-West K. Factors influencing MMR vaccination decisions following a mumps outbreak on a university campus. Vaccine. 2006;24(24):5183-91.

27. Nyhan B, Reifler J, Richey S. The role of social networks in influenza vaccine attitudes and intentions among college students in the southeastern united states. J Adolescent Health. 2012:51(3):302-4.

28. Pennie RAOCA, Garvock MJ, Drake ER. Factors influencing the acceptance of hepatitis B vaccine by students in health disciplines in Ottawa. Canadian Journal of Public Health. 1991;106:529-35.

29. Sun WY, Sangweni NB, Butts G, Merlino M. Factors affecting immunization status of college students in New York City (NYC). Soc Work Health Care. 2001;33(1):87-100.

30. Paulussen TGW, Hoekstra F, Lanting Cl, Buijs GB, Hirasing RA. Determinants of Dutch parents' decisions to vaccinate their child. Vaccine. 2006;24(5):644-51.

31. Hoger onderwijs; ingeschrevenen, studierichting, leeftijd [http://statline.cbs.nl/ Statweb/publication/?DM=SLNL\&PA $=70943$ ned\&D1 $=0 \& D 2=0 \& D 3=0 \& D 4=0-$ $2 \& D 5=0 \& D 6=1,5,38-39,272,276,278 \& D 7=a \& W=T$

32. Fiebelkorn AP, Lawler J, Curns AT, Brandeburg C, Wallace GS. Mumps postexposure prophylaxis with a third dose of measles-mumps-rubella vaccine, orange county. New York Emerg Infect Dis. 2013;19(9):1411-7.

33. Nelson GE, Aguon A, Valencia E, Oliva R, Guerrero ML, Reyes R, et al. Epidemiology of a mumps outbreak in a highly vaccinated island population and use of a third dose of measles-mumps-rubella vaccine for outbreak control-Guam 2009 to 2010. Pediatr Infect Dis J. 2013;32(4):374-80.

34. Ogbuanu IU, Kutty PK, Hudson JM, Blog D, Abedi GR, Goodell S, et al. Impact of a third dose of measles-mumps-rubella vaccine on a mumps outbreak. Pediatrics. 2012;130(6):E1567-74.

35. International Standard Classification of Education, 1997 (ISCED). [http://www.cbs.nl/nl-NL/menu/methoden/classificaties/overzicht/isced/ international-standard-classification-of-education-isced.htm]

\section{Submit your next manuscript to BioMed Central and take full advantage of:}

- Convenient online submission

- Thorough peer review

- No space constraints or color figure charges

- Immediate publication on acceptance

- Inclusion in PubMed, CAS, Scopus and Google Scholar

- Research which is freely available for redistribution 